\title{
AC 2009-657: TRAINING ENGINEERING LEADERS THROUGH INTERNATIONAL COMMUNITY DEVELOPMENT PROJECTS
}

\section{Meagan Vaughan, University of Texas, Austin}

Meagan Vaughan is a graduate student in the Mechanical Engineering Department at the University of Texas at Austin. While researching lower limb prosthetic socket design, she also helps oversee community development projects as a teaching assistant.

\section{Janet Ellzey, University of Texas, Austin}

Dr. Janet Ellzey is a professor of Mechanical Engineering at the University of Texas at Austin. In addition to conducting research in combustion, she is Assistant Dean for International Engineering Education. She is also faculty adviser to the University of Texas chapter of Engineers Without Borders. 


\title{
Training Engineering Leaders through International Community Development Projects
}

\begin{abstract}
Future engineering leaders will need to apply their skills across many economic and cultural boundaries, yet these experiences are often overlooked in a traditional engineering education. Service learning, or community service integrated into the academic program, provides a unique opportunity for students to apply their engineering skills to problems facing underserved communities worldwide. At the University of Texas at Austin, students have shown their enthusiasm for these activities through the campus chapter of Engineers Without Boarders (EWB). In 2008, a multidisciplinary design course with both technical and cultural components was developed with a EWB project as its focus. During the semester, students worked on a water treatment and distribution system for a girls' school, Saker Baptist College (SBC), in Cameroon, Africa. Non-enrolled students were also given the opportunity to participate on an as-needed basis. Students were divided according to skill level and preference into one of five project teams. These teams were intended to cover the major areas of product design, project planning, community/customer relations, and community health and education. Class time was divided among lectures from international volunteers, discussions of west African literature and politics, and project work. At the completion of the semester, students were prepared to travel to Cameroon to complete the assessment phase of the project. Supervision was provided by a faculty member, a teaching assistant, a professional engineer, and two student project leaders to ensure completion of the semester's work. Student feedback to date has been positive and course instructor survey results will be used to further develop service learning opportunities for engineering student leaders.
\end{abstract}

\section{Introduction}

Service Learning is widely accepted as a blending of community based service with coursework allowing students to enhance their academic learning experience through direct community engagement. It is not simply volunteering on a community service project. Though very beneficial to community development, service projects are not directly linked to course content nor require the technical rigger of Service Learning programs. The motivation behind Service Learning is simply that individuals cannot be complacent in the face of need and higher education can be a dynamic force in encouraging community service ${ }^{1}$. This integration of service with coursework has been reported to add significantly to the benefits of community service ${ }^{2}$. The reported benefits of Service Learning are promising. Improved student retention ${ }^{3}$, interpersonal skills ${ }^{4}$, cultural and racial understanding ${ }^{5}$, academic achievement ${ }^{6}$, sense of identity ${ }^{7}$, sense of social responsibility ${ }^{8}$, commitment to continued service ${ }^{9}$, and involvement from underrepresented populations in engineering ${ }^{10}$ are all among the marked benefits of student participation in Service Learning programs. At the community level, Service Learning programs have been helpful in providing useful service ${ }^{11}$ and strengthening university relations ${ }^{12}$. 
Students at this university are seeking out service opportunities, such as Engineers Without Boarders (EWB), in growing numbers. Started in 2002 by Dr. Bernardo Amadei from the University of Colorado in Boulder, EWB is a humanitarian organization whose goal is to train engineers and engineering students to utilize sustainable and appropriate technologies in serving developing communities ${ }^{13}$. This organization provided the students at the University of Texas at Austin (UT) with an early format through which to begin applying their engineering education to a service oriented application. Several student projects have been conducted by the EWB-UT chapter in locations such as Panama, Mexico, and Africa.

Although service has been integrated into academic programs at other universities, the most common format is a faculty-led program in which one or two faculty members assume responsibility for the project from start to finish including approving the technical plans and traveling with the students ${ }^{14-16}$. In this approach, the faculty is administering the service learning project in much the same manner as they manage graduate research projects. The EWB-UT projects are initiated by students and do not necessarily fit within an individual faculty member's research program. In addition, these projects are often an implementation of existing technology and no research is involved. Thus, the faculty-led model is not easily adaptable to this university. Nonetheless, UT is committed to developing service learning initiatives. In the approach discussed in this paper, the faculty instructor provided the overall management of the project while technical oversight both during the semester and during the trip was provided by other faculty members and professional engineers outside of the university. Another unique aspect of the course was the integration of a cultural component designed to help the students understand the community that they were serving.

The project selected for this Service Learning course was to design a water treatment and distribution system for a girls' school, Saker Baptist College (SBC), in Cameroon, Africa. The project had been initiated by a student who had lived in Cameroon during her childhood and so had a particular connection to the people there. At the time the course began, the students had already taken one trip to SBC to assess the school's water needs. A second assessment trip to take detailed data was scheduled for December 2008. The goal of the course was to prepare the students for this second trip.

In the following sections, the class structure, content, and grading are discussed followed by outcomes and lessons learned. The hope is that the experiences from this course will assist other faculty designing Service Learning courses and to facilitate the development of Service Learning at universities where the faculty-led model may not be appropriate.

\section{Class Structure}

Twenty graduate and undergraduate students, thirteen credit and seven non-credit, were drawn by the service learning opportunity to participate in the project. These students were from Biomedical, Mechanical, Chemical, Civil, and Environmental 
Engineering departments, as well as Biology and Anthropology. To help maintain focus on the critical components of the project, five teams were formed from the students: Project Planning, Design, Water Treatment, Health and Education, and Community Relations. The Project Planning team was responsible for long term planning, team coordination, and logistics. This team helped maintain the momentum of the project as a cohesive unit. The Design team was divided into two sub-teams responsible for the primary upgrades to the water system at SBC: the water storage tanks and pump. These Design sub-teams also worked in conjunction with a Water Treatment team responsible for customizing a water treatment system for SBC. In addition to providing the students at SBC with an increased potable water supply, a Health and Education team developed educational materials about water conservation and sanitary practices. Working with all of these teams was a smaller Community Relations team whose role was to help the members understand Cameroonian culture and history. Students were assigned to teams based on skills, interest, and need. To facilitate team assignments, each student completed a Team Assignment Form. This form included an open-ended question about prior education and relevant skills to aid in placement.

\section{Project Management and Oversight}

Leadership of the project required management at both the student and faculty level. Student leadership of the entire project began with two Project Leaders who had been previously selected by EWB-UT. These project leaders worked closely with both UT and SBC administration as a liaison for the team members. Leaders for the individual teams were either self-nominated on the Team Assignment form or nominated by other group members. Final selection of Team Leaders was a joint decision of the faculty member and the Project Leaders. The Team Leaders were responsible for motivating team members, organizing group work, and maintaining communication with other project leadership.

In addition to the Student Project Leaders who primarily helped organize the project, a Teaching Assistant (TA) was hired to aid the Faculty member in organizing class assignments, project work, and guest speakers. The TA met with the students regularly during their class time and helped facilitate problem solving and foster teamwork. This was a key role as it helped the students maintain communication between teams and motivated them when they had questions. As a graduate student in the Mechanical Engineering department with design experience, the TA's participation on a similar student design project designing locally manufactured biomedical devices for developing countries proved beneficial. The TA's experience provided the students an additional resource in conjunction with the engineering and cultural content of the course as they prepared for their assessment trip.

Additional technical oversight was also provided by local engineering professionals. Members of the local professional chapter of EWB visited the class and provided guidance to individual teams. Working with these practicing engineers provided the students with additional insight on system design, project planning, and other relevant issues. When more detailed information was needed on the parameters of the system to 
be designed, a certified Water Treatment Specialist reviewed design concepts with the teams. In the middle of the semester, a local Professional Engineer with experience working in developing countries was also selected to act as the traveling professional to provide oversight during the Assessment Trip II.

\section{Course Content}

Two-fold in its purpose, the course content was designed to include both engineering and cultural elements. The engineering content focused on enabling students to apply the knowledge gained through coursework to their particular project applications. To support the students in understanding the needs of their target community, the cultural element of the course was formulated to provide students a basic understanding of Cameroonian culture.

\section{Engineering Content}

Much of the coursework was modeled after the capstone design course commonly required of senior level students at the university. As such, application of knowledge gained from previous coursework, as well as development of new skills particular to the project, were key components of the engineering course content. Students were required to complete research on topics such as water treatment, which required a literature review and interviews with EWB Professionals and a Water Treatment Specialist. In addition, they learned to use engineering software, such as Pipe2000 and SolidWorks ${ }^{\circledR}$, as needed to fulfill the requirements of their project. In addition, students had to rely on technical skills learned during courses such as Fluids, Project Management, and Mechanical Systems and Design. Other skills, such as surveying, were also developed during special training sessions. Project planning tools, such as Gantt charts, were used to help the teams organize and complete work before their Assessment Trip II.

Technical presentation skills were also developed through each of three presentations given by the teams during the semester. The primary purpose of these presentations was to facilitate communication of goals and progress to the other teams and to the instructors. In the first presentation students shared their initial goals for the semester. These were modified during the class discussion that followed to ensure that all aspects of the project were covered. A second presentation in mid-semester allowed for assessment of student progress. The Final Presentation was given at the end of semester to report on the work completed and the remaining tasks necessary for the assessment trip.

Although the course was originally tailored after the capstone design course, there were significant differences between that course and the Service Learning course. First, unlike the capstone design project, students in the EWB course were responsible for not only the design but also the construction of the project. Second, the capstone projects are generally presented to an industrial partner who also verifies the design. These differences mean that the design of the EWB project must be checked by qualified faculty and/or a professional in the appropriate field. 


\section{Cultural Content}

Since success of an engineering project requires a thorough understanding of customer needs, a part of the class time was devoted to studying Cameroonian and west African culture. A majority of students on the project had never traveled to Cameroon or worked closely with west African culture so this introduction was particularly important. To provide some insight into the local culture, the students read several selections from west African literature and viewed a west African film. In addition, guest speakers provided personal experiences of working in Africa or in developing regions in other parts of the world.

Guest speakers, each with experience working in developing countries, gave brief presentations about their experiences and then opened the floor for discussion to address issues of interest to the students. Two of these speakers were graduate students from the Mechanical Engineering department at the University of Texas at Austin who had participated on similar student design projects in developing countries. Their experiences helped the students get an idea of team organization and what to expect while working as undergraduate students in another culture. Two Peace Corp volunteers, one of whom served in Cameroon, also shared their experiences with the students. These speakers were very helpful in discussing both the challenges and rewards of working with an underserved community. The speakers also emphasized the importance of communication and local support.

In addition to personal experiences from the guest speakers, African literature was used to provide students with a broader understanding of the of the host country. The books were selected with the assistance of a graduate student in the French department who specialized in west African literature. In the six books selected, three were included that were commonly read by the students at SBC. This selection was intentional as it could provide a link to the SBC students. Students were divided into three reading groups each of which read two of the six assigned texts (Table 1).

Table 1 Assigned Reading

\begin{tabular}{|l|}
\hline $\begin{array}{l}\text { 1. Achebe, Chinua. Things Fall Apart. New York: } \\
\text { Anchor Books, } 1959 .\end{array}$ \\
\hline $\begin{array}{l}\text { 2. Oyono, Ferdinand. Houseboy. Oxford: Heinemann } \\
\text { Educational Publishers, 1960. }\end{array}$ \\
\hline $\begin{array}{l}\text { 3. Head, Bessie. A Question of Power Oxford: } \\
\text { Heinemann Educational Publishers, } 1974 .\end{array}$ \\
\hline $\begin{array}{l}\text { 4. Beti, Mongo. The Poor Christ of Bomba. Oxford: } \\
\text { Heinemann Educational Publishers, } 1956 .\end{array}$ \\
\hline $\begin{array}{l}\text { 5. Makuchi, Juliana. Your Madness Not Mine: Stories } \\
\text { of Cameroon. Athens: Ohio University Press, 1999. }\end{array}$ \\
\hline $\begin{array}{l}\text { 6. Cesaire, Aime. Notebook of a Return to the Native } \\
\text { Land. Wesleyan University Press, 2001. }\end{array}$ \\
\hline
\end{tabular}


Reading guides with questions for each book were provided to the students in advance. The reading groups then led discussions with the entire class in hopes of sharing their insight into Cameroonian culture. To this same end, a film, Africa I Will Fleece You, 1992 by Jean-Marie Teno, was also viewed by the students as an additional resource on African culture. Together the guest speakers, assigned reading, and film viewed were meant to provide the team members with a glimpse of the culture in which they would be working during the Assessment Trip II.

\section{Grading}

Assignment of grades at the culmination of the semester was based on student presentations, attendance, and class participation. The student presentations included the Initial Goals, Mid-semester Design, and Final presentations as well as participation in the book discussions. As to attendance, all enrolled students were required to attend each of the class meetings. Besides contributing during class discussions and project work, participation grades were determined based on work recorded on Weekly Reports submitted by the students. In these Weekly Reports students documented the work completed that week, a summary of work completed to date, and a proposal of work for the next week. Each entry was accompanied by a brief explanation of the purpose of the work completed or yet to be completed. Each of these contributed to the final grade assigned to each student at the end of the semester for the two credit hours the students received for this course.

\section{Outcomes}

After spending the fall semester preparing both technically and culturally, six students and a professional engineer departed for Cameroon, Africa, in late December 2008 to complete a second Project Assessment. The purpose of the trip was to determine the viability of partnering with SBC and come to an agreement as to the terms of the project. In addition, they sought to collect data relevant to the design and necessity of a water system. They also planned to survey the SBC students about sanitation practices and hand out educational booklets with material on healthy habits and on the EWB project. Upon arrival, however, the SBC administration determined that the school had enough resources to complete the project without the help of EWB-UT. The UT group agreed to complete surveying and water quality data and provide this information to the administration to assist in the design of the water system. Since this was less work than the group had originally planned, they used the remainder of their time in Cameroon to forge relationships with other communities and to assess other possible projects.

Feedback from students in general was very positive about the blending of this design project into the classroom but still felt that there is room for improvement. A large majority of students did report that the course helped them to be better prepared for working on the project and that it helped them to better understand Cameroonian culture. Students felt that the input of guest speakers was very insightful but that the topics could be more focused. For example, students showed great interest in having speakers that 
would speak on basic engineering design processes, water treatment or other issues specific to the project and not just on cultural issues. A similar feeling was expressed about assigned book readings. Students felt that having a smaller number of books focused on Cameroon that all students read would be more beneficial than trying to cover an array of books that not all students read. This was because they did not feel as though they learned much from the book discussions if they had not also read the book and therefore the discussions were not an effective use of class time. The students who were not enrolled in the class but participated in the project did not, in general, want to participate in the book and cultural discussions. In the future, the responsibilities of the students who work on the project but are not enrolled need to be more clearly defined. A suggested solution would be to use one class meeting per week for guest speakers and discussion of books with the other for project related work, and make attendance in the first course meeting optional but recommended for non-credit students. Another improvement to the course would be a better implementation of Weekly Reports. In the existing format, Weekly Reports are only read in detail by the TA. In the future, having students also submit reports to team leaders, project leaders, and faculty would help increase internal communication and potentially identify problems early.

\section{Lessons Learned}

This preliminary attempt at blending an interdisciplinary engineering student design project into the classroom format provided several key issues for consideration in future attempts. The greatest of these was the importance of communication with local contacts. Many of the difficulties encountered during the project resulted from misunderstandings and ineffective communication with SBC administration. In the case of this project, there were multiple organizations at the school - alumni, parents, and administration - with differing levels of authority over the project at SBC. An option that could help improve communication could be working with an intercessory, such as from a Non-Governmental Organization (NGO) already established in the region, to provide local support. Established NGOs have the connections to facilitate the logistics and to provide training on local cultural issues. In addition to working with a partner organization, having a professional engineer involved with the design project well before travel is important. Selection of a traveling professional, either from faculty or industry, a few weeks prior to departure does not allow for a relationship to be fostered and therefore the trust of the group to be established. Early engagement also allows the professional to have a better understanding of the project both to be able to provide guidance while on site as well as step in as moderator with the community if needed. In addition to a traveling professional, some sort of technical oversight of design work completed by the project teams needs to be provided, prior to any sort of implementation. At UT, we are working to establish a technical oversight committee in the Engineering Department. This committee, consisting of faculty from various departments, will provide input and final approval of the student designs prior to implementation.

Though the course structure was an effective first attempt, improvements based on student and instructor feedback should be made. The inclusion of both engineering and cultural content was well received by the students. However, students felt that the 
focus of the content needs to be even more specific to the project at hand rather than on general case projects in developing countries. In addition, making a stronger distinction between the cultural and technical components of the class was important to the students. This course was an important first step in developing a service learning program where students can receive course credit for their work associated with community projects.

\section{Conclusion}

Twenty students from several engineering departments plus one anthropology student participated in a course designed to apply engineering to a service application. The framework of the course was focused not only on the engineering design of a water treatment system but also on the cultural aspects of working with the Saker Baptist College in Cameroon, Africa. Highly received by the students, the lessons learned will be incorporated into future efforts to develop service learning in the Cockrell School of Engineering at the University of Texas.

\section{References}

1 President's Declaration on the Civic Responsibility of Higher Education. May 2007. Campus Compact. 19 Mar. $2009<$ http://www.compact.org>.

2 Astin, Alexander W. Executive Summary: How Service Learning Affects Students. Jan. 2000. Higher Education Research Institute, 19 Mar. 2009 <http://www.gseis.ucla.edu/heri/PDFs/rhowas.pdf>.

3 Piket-May, Melinda, and Avery, James. "Service Learning First Year Design Retention Results". Proc of ASEE/IEEE Frontiers in Education Conference., Oct. 2001.

${ }^{4}$ Vogelgesang, L. J., and Astin, A. W. Comparing the Effects of Service-Learning and Community Service. Michigan Journal of Community Service Learning, 7, pp. 25-34. 2000.

5 Vogelgesang, L. J., and Astin, A. W. Comparing the Effects of Service-Learning and Community Service. Michigan Journal of Community Service Learning, 7, pp. 25-34. 2000.

${ }^{6}$ Vogelgesang, L. J., and Astin, A. W. Comparing the Effects of Service-Learning and Community Service. Michigan Journal of Community Service Learning, 7, pp. 25-34. 2000.

7 Rockquemore, K. A., \& Schaffer, R. H. Toward a Theory of Engagement: A Cognitive Mapping of Service-Learning Experiences. Michigan Journal of Community Service Learning. 7, pp. 14-25. 2000.

8 Astin, Alexander W, Executive Summary: How Service Learning Affects Students, Jan. 2000. Higher Education Research Institute. 19 Mar. 2009 <http://www.gseis.ucla.edu/heri/PDFs/rhowas.pdf>.

9 Astin, Alexander W, Executive Summary: How Service Learning Affects Students, Jan. 2000. Higher Education Research Institute. 19 Mar. 2009 <http://www.gseis.ucla.edu/heri/PDFs/rhowas.pdf>.

${ }^{10}$ Duffy, John. "Village Empowerment: Service Learning with Continuity". International Journal for Service Learning in Engineering. 3(2). pp. 1-12. Fall 2008. 
${ }^{11}$ Driscoll, A., Holland, B., Gelmon, S., \& Kerrigan, S. An Assessment Model for Service-Learning: Comprehensive Case Studies of Impact on Faculty, Students, Community, and Institutions. Michigan Journal of Community Service Learning, 3, pp. 66-71. (1996).

${ }^{12}$ Driscoll, A., Holland, B., Gelmon, S., \& Kerrigan, S. An Assessment Model for Service-Learning: Comprehensive Case Studies of Impact on Faculty, Students, Community, and Institutions. Michigan Journal of Community Service Learning, 3, pp. 66-71. (1996).

${ }^{13}$ Nott, Willard, et al. Engineers Without Borders - USA, "Learning Through Humanitarian Service to Underdeveloped Countries", Proc. of International Conference on Engineering Education, 2007.

${ }^{14}$ LeTourneau University, Longview, TX, 19 Mar. 2009 <www.letu.edu>.

${ }^{15}$ Villanova University, Villanova, PA, 19 Mar. 2009 $<$ http://www.villanova.edu/artsci/college/servicelearning/>.

${ }^{16}$ Assistive Technology Resource Center, Worchester Polytechnic Institute, Worcester, MA, 19 Mar. 2009 $<$ http://www.me.wpi.edu/Research/ATRC/>. 